\title{
Experimental study on annular cylindrical tuned liquid dampers for vibration control under different excitation angles
}

\author{
Ahmet Can Altunışık*iD, Volkan Kahya ${ }^{\text {iD }}$, Ali Yetişken \\ Karadeniz Technical University, Faculty of Engineering, Department of Civil Engineering, 61080 Trabzon, \\ Turkey
}

\begin{abstract}
This work aims to experimentally show the effectiveness of annular cylindrical tuned liquid dampers (ACTLDs) on the classical tuned liquid column dampers (TLCDs) under the effect of inclined ground motion. For experimental measurements, a single-story model structure constituted by two plates at the top and bottom connected by four columns was constructed. Since the water length within the tuned liquid dampers (TLDs) is a very important parameter that affects the performance of the absorber, ACTLD and TLCD devices were designed such that their total water lengths be equal for comparison purposes. The modal characteristics of the model structure were determined by ambient vibration tests. The resonant frequency, head-loss coefficient, damping ratio, and water height-frequency diagram of ACTLD and TLCD devices were obtained experimentally through the shaking table tests. Then, the shaking table tests on the model structure with and without the absorbers under consideration were performed to obtain the acceleration and displacement time-histories and the damping ratio for the coupled system. In experimental tests, different excitation directions from $0^{\circ}$ to $90^{\circ}$ were considered. Results of the study show that ACTLDs are better than TLCDs at suppressing vibrations caused by ground motions acting on the structure at oblique angles.
\end{abstract}

\section{Keywords}

Annular cylindrical tuned liquid damper; Tuned liquid column damper; Ambient vibration test; Shaking table; Damping

Received: 3 July 2021; Accepted: 21 July 2021

ISSN: 2630-5763 (online) (C) 2021 Golden Light Publishing All rights reserved

\section{Introduction}

Vibration control is essential when designing buildings especially if they are tall, which are subjected to substantial vibration due to wind and earthquakes, and may be exposed to resonant vibrations with low-frequency content. To reduce the harmful effects of the resonant vibrations on the structures, mass dampers [1-5], liquid dampers [69], base isolators [10-12], and other supplemental damping systems [13] are among the various alternatives. This paper focuses on one of these methods, Tuned Liquid Damper (TLD), which is water confined in a container that uses the sloshing energy of the water to reduce the dynamic response of the structure during excitation.

As a special case of TLD, Tuned Liquid Column Dampers (TLCDs) having a U-shaped tube containing a liquid that is usually water has been developed. The TLCD can reduce the structural vibrations through the motion of liquid residing in the container which counteracts the action of the external excitations [14]. The damping effect of the

* Corresponding author

Email: ahmetcan8284@hotmail.com 
TLCD is produced by the head loss of hydraulic pressure of the liquid due to the orifice installed inside of the container and the viscous action in the boundary layers. The application of TLCDs on civil engineering structures was first proposed by Sakai and Takeda [15]. Balendra et al. [16] studied the effectiveness of TLCD for vibration control of towers. Chang and Hsu [17] investigated the control performance of TLCDs for buildings. Gao et al. [6] developed a numerical method including the nonlinearity of governing equation to show the effectiveness of TLCD in controlling structural vibrations. Hitchcock et al. [18] investigated the characteristics of liquid column absorbers (LCVAs) and found that they are dependent on the geometrical configuration of LCVA. They also investigated the bidirectional configuration LCVAs. They studied the performance of various configurations of the bidirectional LCVA experimentally to understand the parameters which allow optimization [19]. Yalla and Kareem [20] performed an experimental study to examine the performance of a prototype semi-active TLCD. Wu et al. [21] proposed a practical guideline for TLCD design in damped single-degree-of-freedom structures under wind excitations. Wu et al. [22] presented the optimal design parameters of TLCDs with non-uniform cross-sections for application to an SDOF structure in horizontal motion. Chaiviriyawong et al. [23] simulated TLCDs using an elliptical flow path estimation method. A modified version of TLCD is proposed by Al-Saif et al. [24] as a passive vibration control device at low-frequencies. Mousavi et al. [25] carried out a detailed investigation on the optimum geometry of tuned liquid column-gas damper for vibrations of an offshore jacket platform under seismic excitations. Sarkar et al. [26] proposed a passive hybrid damper derived from a pendulum-type tuned mass damper (TMD) and a TLCD. Mensah and Dueñas-Osorio [27] improved a dynamic model of the wind turbine to accommodate single/multiple TLCD in controlling excessive vibrations. Bigdeli and Kim [28] compared three passive vibration absorbers such as TMD, TLD, and TLCD experimentally. Di Matteao et al. [29] developed a formulation for the response of structural systems controlled by TLCD devices based on the mathematical tool of fractional calculus. Behbarani et al. [30] showed the effect of TLCD with maneuverable flaps on vibration control of structures by carrying out shaking table tests on a prototype structure with and without the absorber.

Earthquake-induced ground motions propagate in longitudinal, transversal, and vertical directions. Many design codes suggest the simultaneous effect of two lateral components is considered to be parallel to the sides of the structure. Dynamic absorbers are also installed on the structure as being parallel to its sides. However, structures may not be always excited by ground motions orthogonal to their sides, i.e., in $x$ - and $y$-directions, due to their positions in the plan on the ground. For this reason, in dynamic analyses, it should be considered that the structure can be excited by the ground motions with different directions in the plan. The abovegiven literature is on vibration control of a structure by TLDs under one-directional base excitation, and there is no literature, to the best of authors, that exists on this topic. Recently, Altunışık et al. [8] performed the experimental evaluation of TLCDs installed on a single-story structure exposed to the ground motions with different directions. They also studied experimentally the performance of annular cylindrical liquid column dampers (ACTLDs) for vibration suppression of structures exposed to ground motion with different directions [31].

This study compares the vibration control effectiveness of ACTLDs and TLCDs installed to structures subjected to inclined ground motions. A series of experiments were performed on a singlestory structure constituted by two plates at the top and bottom connected by four columns. Since the water length within the tuned liquid dampers (TLDs) is a very important parameter that affects the performance of the absorber, ACTLD and TLCD devices were designed such that their total water lengths be equal for comparison purposes. The modal characteristics of the model structure were determined by ambient vibration tests. The resonant frequency, head-loss coefficient, damping ratio, and water height-frequency diagram of 
ACTLD and TLCD devices were obtained experimentally through the shaking table tests. Then, the shaking table tests on the model structure with and without the absorbers under consideration were performed to obtain the acceleration and displacement time-histories and the damping ratio for the coupled system. In experimental tests, different excitation directions between $0^{\circ}$ and $90^{\circ}$ were considered. For numerical evaluation, finite element (FE) analyses were also performed via ANSYS ${ }^{\circledR}[32]$. In FE modeling, the absorbers were assumed to be added mass. Comparisons are made to investigate the control performances of TLCD and ACTLD devices due to inclined ground motion effects.

\section{Theoretical background for TLCDs}

For comparison of TLCD and ACTLD absorbers, here, we gave a brief theoretical formulation for the design of TLCD. Fig. 1 shows a schematical representation of TLCD. Using the energy principle associated with Lagrange's equations, liquid surface motion in a TLCD can be given by [6].

$$
\ddot{y}(t)+\frac{1}{2} v|\dot{y}(t)| \dot{y}(t)+\omega_{0}^{2} y(t)=\frac{b}{L_{e}} \ddot{x}_{g}(t)
$$

where $\ddot{x}_{g}(t)$ is the acceleration practiced to TLCD, $\ddot{y}(t), \dot{y}(t)$ and $y(t)$ are the acceleration, velocity, and displacement of liquid inside TLCD, respectively, $v$ is the cross-sectional ratio $\left(A_{v} / A_{h}\right)$ in which $A_{v}$ and $A_{h}$ are the vertical and horizontal cross-sectional areas of TLCD, respectively, $\omega_{0}$ is the natural frequency of absorber, and Le is the total length of liquid, e.g., water, in TLCD, which can be calculated by

$$
L_{e}=2 h+v b
$$

where $h$ and $b$ are the vertical and horizontal lengths of liquid columns. The natural frequency of TLCD can be determined by

$$
\omega_{0}=\sqrt{\frac{2 g}{L_{e}}}
$$

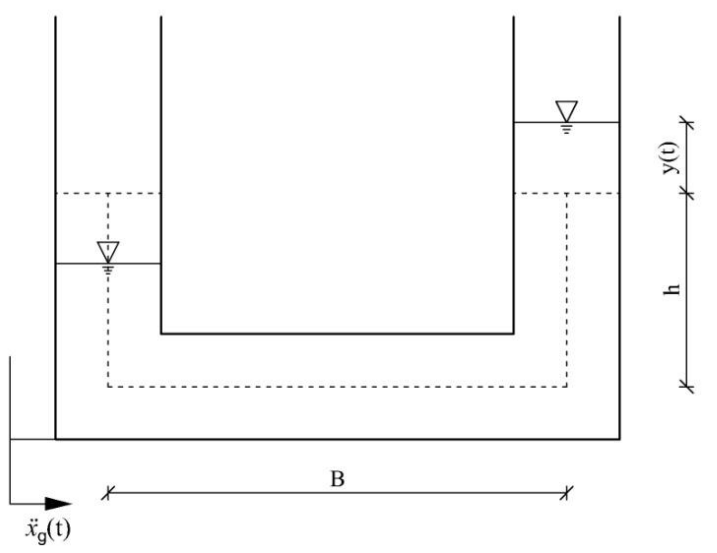

Fig. 1. Configuration of a TLCD absorber

where $g$ is the acceleration of gravity. Eq. (3) shows that the total water length directly affects the natural frequency of TLCD.

\section{Experimental setup and implementation}

In the experimental measurements, a steel singlestory structure consisting of two plates and four columns was constructed. Fig. 2 shows some laboratory views and physical properties of the model structure. Dimensions of the top and bottom plates are $600 \times 600 \times 5 \mathrm{~mm}$ and $300 \times 300 \times 10 \mathrm{~mm}$, respectively. Four columns with $1000 \times 50 \times 5 \mathrm{~mm}$ dimensions were welded to the top and bottom plates. Bolt holes with a diameter of $10 \mathrm{~mm}$ were drilled in the bottom plate to simulate exposure to inclined ground motion as shown in Fig. 2.

Two different types of dynamic absorbers, TLCD and ACTLD, were designed for the measurements. Fig. 3 and Fig. 4 show the physical dimensions of these two absorbers, respectively. TLCD absorber was made of glass material and has $130.75 \mathrm{~N}$ weight. In the design of ACTLD, the total water length was assumed to be equal to that of the TLCD since each longitudinal section of ACTLD represents a U-shape as in TLCD (see Fig. 4). To give a cylindrical form to ACTLD, steel molds were used. Four half-cylinder glasses with $360 \mathrm{~mm}$ inner and $540 \mathrm{~mm}$ outer diameter were processed and glued to each other. Twelve wooden elements, each has $10 \times 10 \mathrm{~mm}$ rectangular cross-section, were used to connect the inner and outer cylinders. To facilitate the montage, the base glass was made of a 
$600 \times 600 \mathrm{~mm}$ rectangular section. The weight of the ACLTD is $279.4 \mathrm{~N}$. Rulers were placed on the surface of both absorbers to measure the water level during experiments. Fig. 5 shows some views of TLCD and ACTLD absorbers designed.
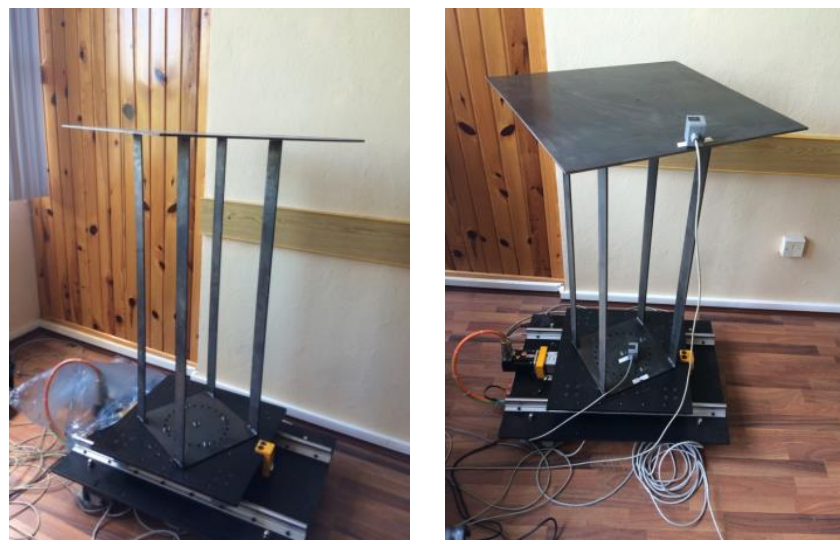

(a) Some laboratory views of the model structure installed on the shaking table
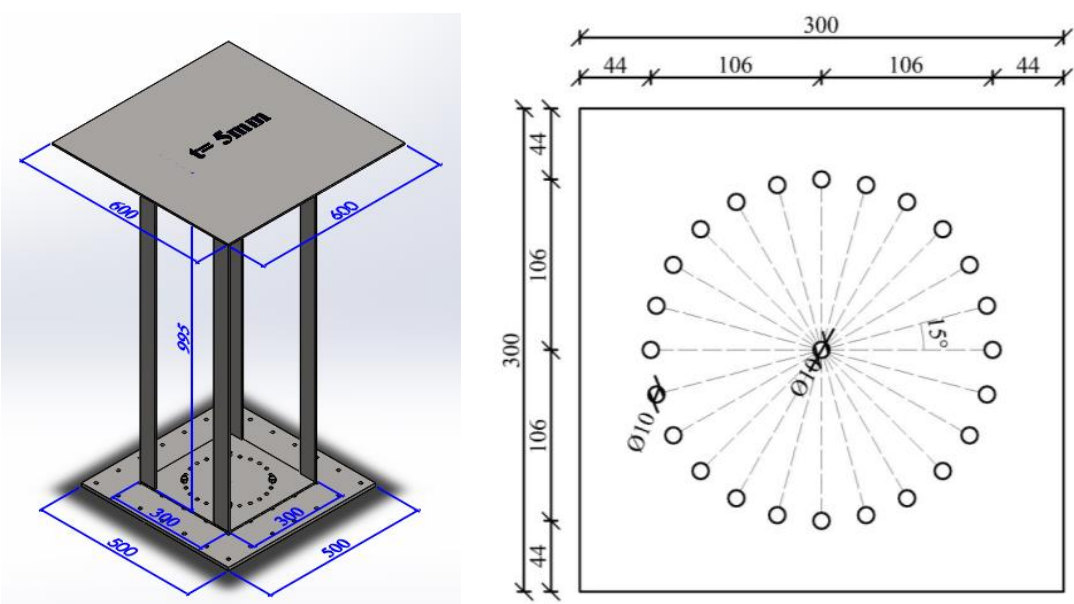

(b) Dimensions of the model structure and details of the bottom plate (units in $\mathrm{mm}$ )

Fig. 2. Laboratory views and physical dimensions of the model structure
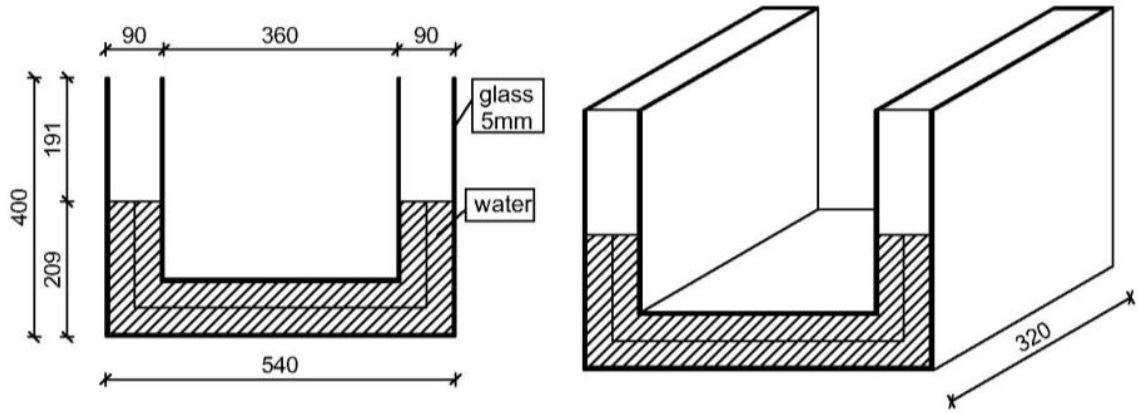

Fig. 3. Geometrical properties of the TLCD (units in $\mathrm{mm}$ ) 

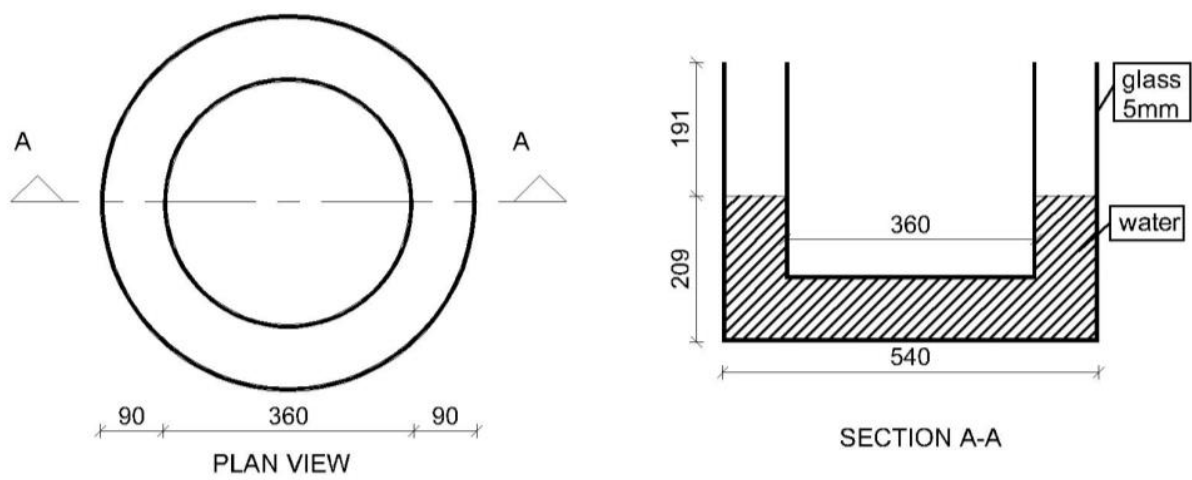

Fig. 4. Geometrical properties of the ACTLD (units in mm)
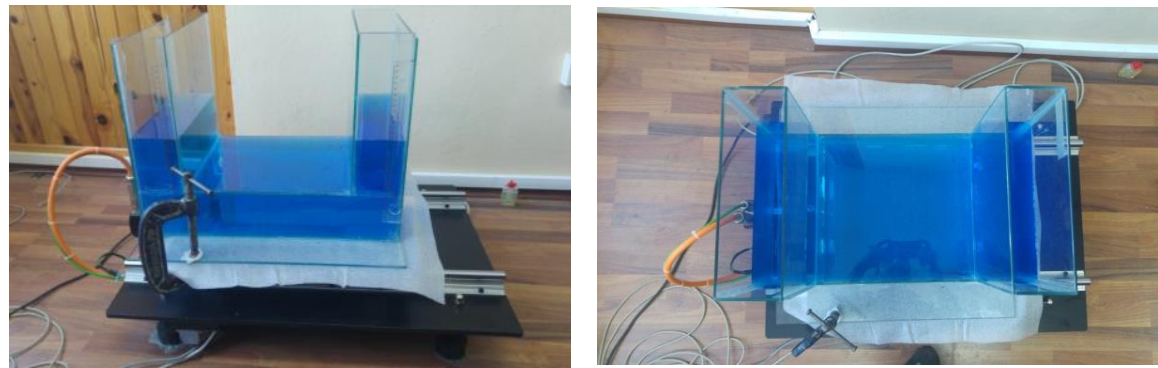

(a) TLCD absorber
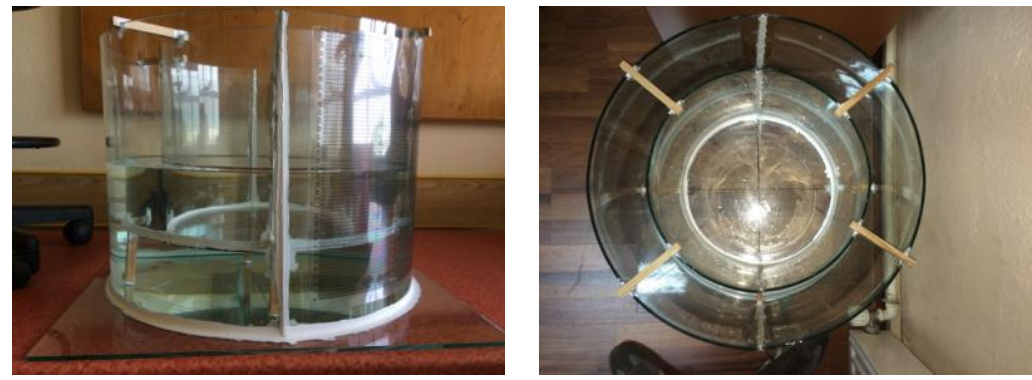

(b) ACTLD absorber

Fig. 5. Some views of TLCD and ACTLD absorbers designed

The experimental analysis was performed in three steps: In the first step, via the operational modal analysis (OMA), the natural frequencies and damping ratios of the model structure were obtained. In the measurements, B\&K3560 data acquisition system with 17 channels and B\&K8340 type uni-axial accelerometer were employed. The signals were collected in the data acquisition system and transferred into PULSE software [33] for signal processing. Then, with OMA software [34], the dynamic characteristics of the structure were determined by Enhanced Frequency Domain Decomposition Method (EFDD) in the frequency domain and Stochastic Subspace Identification Method (SSI) in the time domain. In Fig. 6, the singular values of spectral density matrices (SVDSM) of the data set and the average of auto spectral densities (AASD) from EFDD, and the stabilization diagram of the estimated state of space model from SSI are given. Based on these graphs, the first three experimental natural frequencies of the structure are $2.596 \mathrm{~Hz}, 6.916 \mathrm{~Hz}, 8.440 \mathrm{~Hz}$ according to EFDD, and $2.613 \mathrm{~Hz}, 6.901 \mathrm{~Hz}, 8.390$ $\mathrm{Hz}$ according to SSI. As seen, both methods give similar results. 


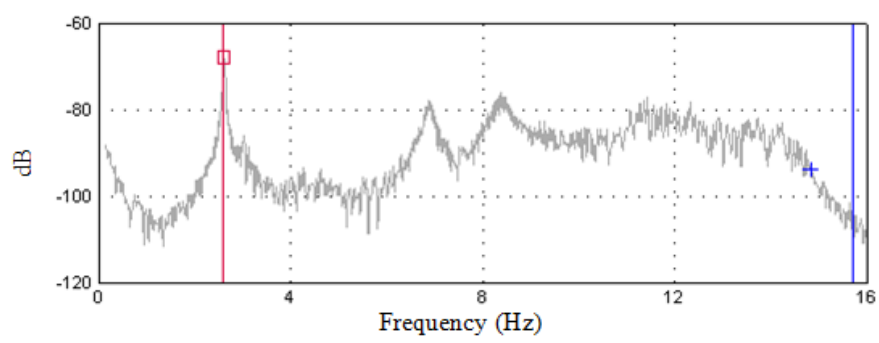

(a) Singular values of spectral density matrices of data set

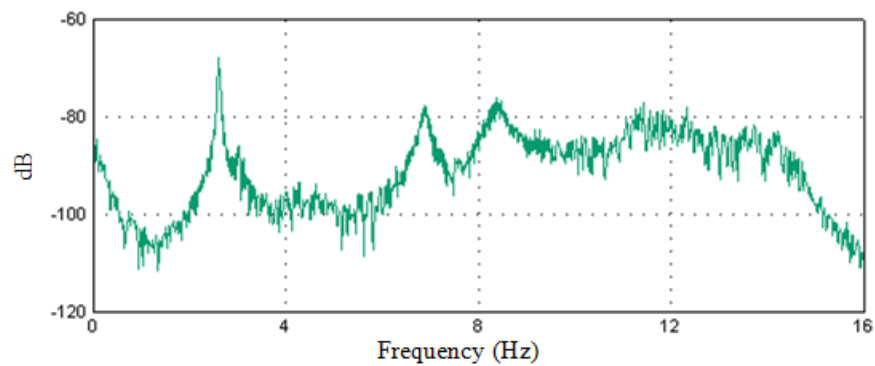

(b) Average of auto spectral densities of data set

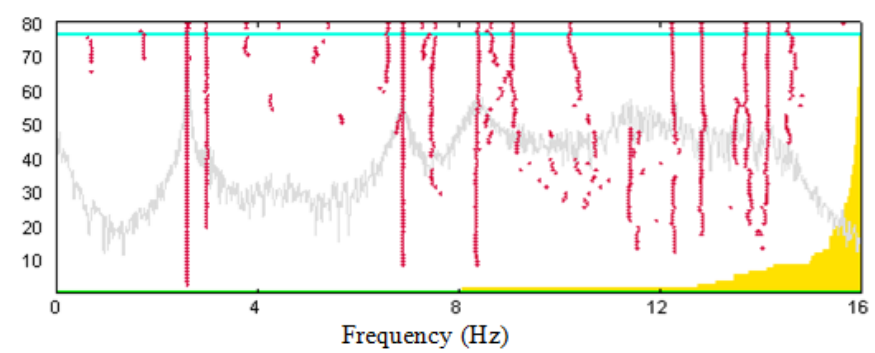

(c) Stabilization diagram of the estimated state of the space model

Fig. 6. EFDD and SSI results for experimental tests on the model structure

In the second step, the resonant frequency, head-loss coefficient, damping ratio, and water height-frequency diagram for TLCD and ACTLD absorbers were determined. To this aim, both absorbers were installed on the shaking table with the aid of four clamps. The shaking table has dimensions of $500 \times 500 \mathrm{~mm}, 500 \mathrm{~N}$ weight and $1000 \mathrm{~N}$ shaking capacity up to $1 \mathrm{~g}$ acceleration. The amplitude of excitation in harmonic tests was limited to ensure that the water surface neither falls below the horizontal portion of the devices nor does water pour out of the system.

For TLCD, the shaking table tests were performed using $16.4 \mathrm{~cm}$ initial water height $(\mathrm{h})$ within $0.60-1.10 \mathrm{~Hz}$ frequency range for $4 \mathrm{~mm}$ and $8 \mathrm{~mm}$ excitation amplitudes, respectively. Table 1 shows the change of maximum water heights with the frequencies of TLCD. As seen, the maximum water height was observed to be $19.8 \mathrm{~cm}$ for $4 \mathrm{~mm}$ excitation amplitude and $21.4 \mathrm{~cm}$ for $8 \mathrm{~mm}$ excitation amplitude. These values correspond to the frequency of the absorber of $0.86 \mathrm{~Hz}$. Thus, the resonant frequency of TLCD was determined to be $0.86 \mathrm{~Hz}$. Using Eq. (3), the resonant frequency of TLCD was calculated to be $0.8 \mathrm{~Hz}$ analytically, which validates the measurements.

The experimental measurements for ACTLD, were performed using $16.4 \mathrm{~cm}$ initial water height (h) within $0.70-1.60 \mathrm{~Hz}$ frequency range for $2 \mathrm{~mm}$ and $4 \mathrm{~mm}$ excitation amplitudes, respectively. Table 2 shows the change of maximum water heights with the frequencies of ACTLD. Following the similar way to the TLCD, it can be concluded that the resonant frequency of ACTLD was determined to be $1.10 \mathrm{~Hz}$ for which the maximum water heights were measured. According to Eq. (3), 
the frequency of ACTLD can be determined as 0.8 $\mathrm{Hz}$, which is far from the experimental frequency, i.e., difference is about $28 \%$. Thus, the formula given by Eq. (3) is not valid for ACTLD absorbers

Table 1. Change of the maximum water heights with the frequencies of TLCD

\begin{tabular}{|c|c|c|c|c|}
\hline \multirow{2}{*}{$\begin{array}{l}\text { Frequency } \\
(\mathrm{Hz})\end{array}$} & \multicolumn{2}{|c|}{4 mm-amplitude } & \multicolumn{2}{|c|}{$8 \mathrm{~mm}$-amplitude } \\
\hline & Measured height $(\mathrm{cm})$ & $\Delta h(\mathrm{~cm})$ & Measured height $(\mathrm{cm})$ & $\Delta h(\mathrm{~cm})$ \\
\hline 0.610 & 16.60 & 0.2 & 17.30 & 0.90 \\
\hline 0.650 & 16.90 & 0.5 & 17.60 & 1.20 \\
\hline 0.700 & 17.10 & 0.7 & 18.10 & 1.70 \\
\hline 0.735 & 17.50 & 1.1 & 18.70 & 2.30 \\
\hline 0.746 & 17.60 & 1.2 & 19.00 & 2.60 \\
\hline 0.758 & 17.80 & 1.4 & 19.30 & 2.90 \\
\hline 0.769 & 17.90 & 1.5 & 19.40 & 3.00 \\
\hline 0.780 & 18.00 & 1.6 & 19.50 & 3.10 \\
\hline 0.790 & 18.30 & 1.9 & 19.90 & 3.50 \\
\hline 0.806 & 18.60 & 2.2 & 20.30 & 3.90 \\
\hline 0.820 & 19.00 & 2.6 & 20.70 & 4.30 \\
\hline 0.830 & 19.20 & 2.8 & 21.10 & 4.70 \\
\hline 0.850 & 19.70 & 3.3 & 21.30 & 4.90 \\
\hline 0.860 & 19.80 & 3.4 & 21.40 & 5.00 \\
\hline 0.870 & 19.70 & 3.3 & 21.30 & 4.90 \\
\hline 0.880 & 19.50 & 3.1 & 21.10 & 4.70 \\
\hline 0.890 & 19.30 & 2.9 & 20.90 & 4.50 \\
\hline 0.900 & 19.10 & 2.7 & 20.70 & 4.30 \\
\hline 0.940 & 18.50 & 2.1 & 19.90 & 3.50 \\
\hline 0.990 & 17.80 & 1.4 & 19.40 & 3.00 \\
\hline 1.030 & 17.60 & 1.2 & 18.70 & 2.30 \\
\hline 1.060 & 17.40 & 1.0 & 18.40 & 2.00 \\
\hline 1.090 & 17.30 & 0.9 & 18.30 & 1.90 \\
\hline 1.100 & 17.10 & 0.7 & 17.80 & 1.40 \\
\hline
\end{tabular}

Table 2. Change of the maximum water heights with frequencies of ACTLD

\begin{tabular}{ccccc}
\hline \multirow{2}{*}{$\begin{array}{c}\text { Frequency } \\
(\mathrm{Hz})\end{array}$} & \multicolumn{2}{c}{2 mm-amplitude } & \multicolumn{2}{c}{4 mm-amplitude } \\
\cline { 2 - 5 } & Measured height $(\mathrm{cm})$ & $\Delta h(\mathrm{~cm})$ & Measured height $(\mathrm{cm})$ & $\Delta h(\mathrm{~cm})$ \\
\hline 0.70 & 16.80 & 0.4 & 17.20 & 0.80 \\
\hline 0.80 & 16.90 & 0.5 & 17.50 & 1.10 \\
\hline 0.90 & 17.10 & 0.7 & 18.40 & 2.00 \\
\hline 0.95 & 17.60 & 1.2 & 19.00 & 4.60 \\
\hline 1.00 & 18.20 & 1.8 & 20.60 & 7.10 \\
\hline 1.05 & 19.90 & 3.5 & 23.50 & 7.70 \\
\hline 1.10 & 21.90 & 5.5 & 24.10 & 5.70 \\
\hline 1.15 & 19.70 & 3.3 & 22.10 & 3.70 \\
\hline 1.20 & 18.60 & 2.2 & 20.10 & 2.30 \\
\hline 1.30 & 17.20 & 0.8 & 18.70 & 1.50 \\
\hline 1.40 & 17.10 & 0.7 & 17.90 & 1.20 \\
\hline 1.50 & 16.90 & 0.5 & 17.60 & 0.80 \\
\hline 1.60 & 16.65 & 0.3 & 17.20 &
\end{tabular}


In the third step of the experimental analysis, the absorbers were installed on the model structure, separately (see Fig. 7), and the resulted coupled system was experienced by a ground motion that was simulated by the shaking table to obtain its acceleration and displacement time histories and damping ratio. Here, the aim is to compare the control performances of both absorbers under the inclined ground motion effect. In the shaking table tests, the bottom plate of the model structure was installed on the shaking table via five bolts, one is in the middle and the others are at the edges as shown in Fig. 2. Thus, the bottom plate can be rotated on the shaking table about the direction orthogonal to its plane to ensure the system be exposed to ground motion in different directions. In shaking table tests, harmonic sinus waves in the resonant frequency with $1 \mathrm{~mm}$ and $2 \mathrm{~mm}$ amplitudes were, respectively, applied during 20 cycles for different directions of ground motion between $0^{\circ}$ and $90^{\circ}$ with an increment of $15^{\circ}$. Acceleration time histories were measured using two sensitive accelerometers located on the top and bottom plates of the structure. The collected records were processed by SeismoSignal Software [35] to obtain the velocity and displacement time histories. Machine vibrations were filtrated by the Butterworth-Bandpass technique. To calculate a realistic damping ratio using the logarithmic decrement method is difficult due to the existence of beat phenomenon in the structure-absorber coupled system. Thus, the damping ratio was determined by the half-power bandwidth method [36]. The selected structural characteristics lead to a linear behavior during excitation, and they were chosen with respect to the limitations imposed by the shaking table in terms of applicable size and tolerable mass. Five different measurements were taken for each case, and the average of the measurements was used to calculate the damping ratio.

At third step, the model structure without absorber was first experienced by ground motion with different directions. Then, the structure with TLCD and ACTLD absorbers was, respectively, subjected to the inclined ground motion. Tables 3-
5 present the maximum accelerations, velocities, displacements, and damping ratios of the model structure with and without absorbers for different angles of excitation.

\section{Results and discussion}

\subsection{Dynamic characteristics of model structure and absorbers}

First, experimental measurements for the model structure were verified by a numerical model. To this aim, finite element modal analysis of the model structure was performed. The three-dimensional finite element model of the structure was constituted in ANSYS ${ }^{\circ}$. In the FE model, the bottom plate of the structure was assumed to be fixed. The modal analyses were performed under a $244.5 \mathrm{~N}$ dead load, and natural frequencies and mode shapes were obtained. Fig. 8 shows the numerically obtained first three mode shapes of vibration. They appeared as $1^{\text {st }}$ bending mode, $1^{\text {st }}$ torsional mode, $2^{\text {nd }}$ bending mode of top plate. Table 6 compares the first three numerical and experimental natural frequencies of the model structure. As seen, the results are in good agreement for the first mode of vibration, which is of importance for our study. According to Table 6, the resonant frequency of the model structure is 2.61 Hz.

Based on the results given in Table 1 and 2, Figs. 9 and 10 show the change in the water level $(\triangle \mathrm{h})$ with the excitation frequency for TLCD and ACTLD absorbers, respectively. In these figures, the maximum increases in the water level are shown for each excitation amplitude assumed. Corresponding damping ratios were calculated by the half-power bandwidth method. After marking $\Delta h_{\max } / \sqrt{2}$ points on the curve to determine the corresponding frequencies $\left(\omega_{1}\right.$ and $\left.\omega_{2}\right)$ on the horizontal axis, as seen in Figs. 9 and 10, the damping ratios $\zeta$ for the considered excitation amplitudes are calculated, respectively. In addition, the head-loss coefficient $\delta$ can be calculated by [16]

$$
\delta=2 L \sqrt{\pi}\left(\frac{\zeta}{\Delta h_{\max }}\right)
$$


using the damping ratios calculated and the maximum water heights, $\Delta h_{\max }$. Tables 7 and 8 give the damping ratios and the head-loss coefficients for each absorber, respectively. As seen, the resonant frequencies for TLCD and ACTLD absorbers are, respectively, determined to be 0.86 $\mathrm{Hz}$ and $1.10 \mathrm{~Hz}$. For both devices, increasing excitation amplitude results in increasing damping. When the excitation amplitude is doubled, damping of TLCD increases $36.5 \%$ while that of ACTLD increases $68.4 \%$. This shows ACTLD provides better damping property than TLCD.

\subsection{Dynamic response of the model structure with and without absorbers}

According to Table 3, the accelerations, velocities and displacements of the structure decrease with increasing the excitation direction of ground motion. This is exactly due to the increasing the column stiffness of the model structure when it rotates from $0^{\circ}$ to $90^{\circ}$. However, there is no significant change in the damping ratio except the excitation direction of $90^{\circ}$ for which the displacements are very small, and the calculation of the damping becomes very difficult.
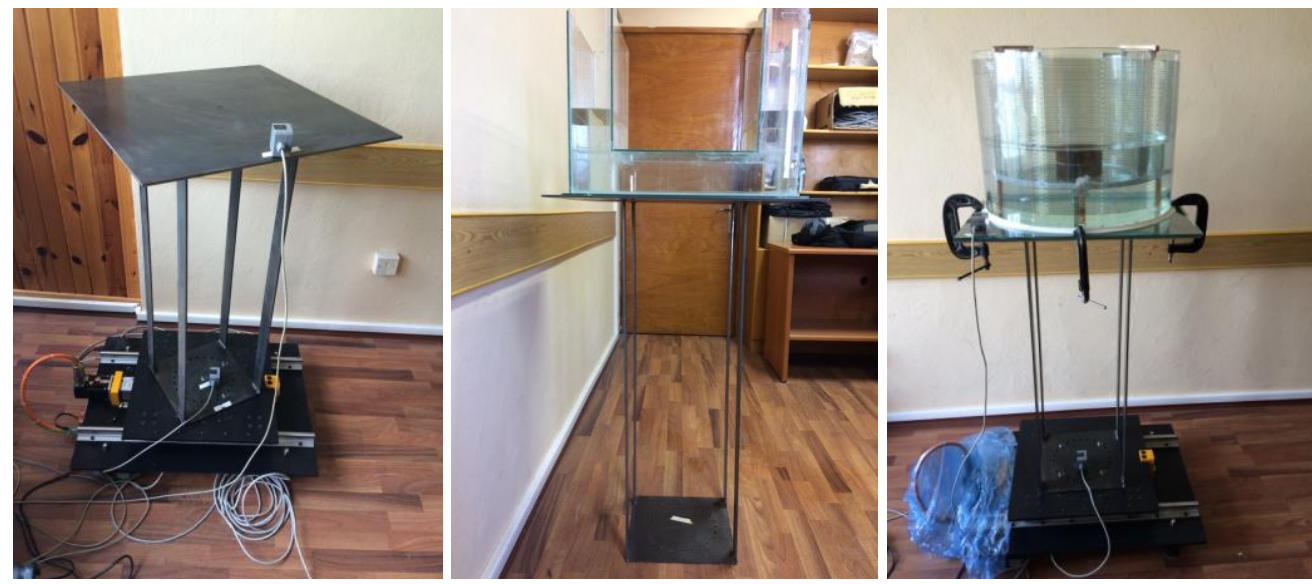

Fig. 7. Some views of TLCD and ACTLD absorbers designed

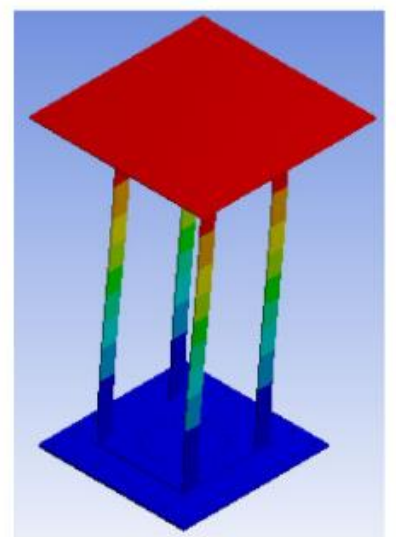

$1^{\text {st }}$ mode shape

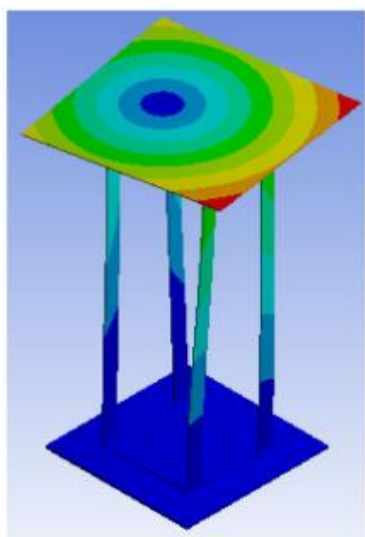

$2^{\text {nd }}$ mode shape

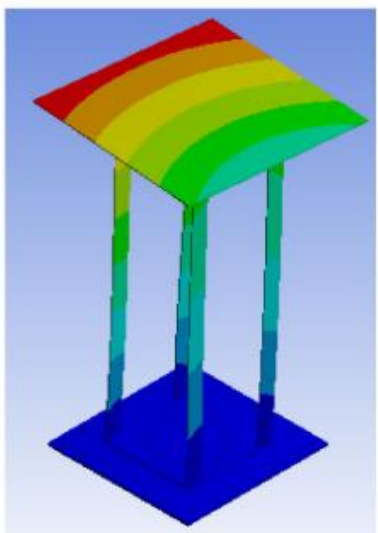

$3^{\text {rd }}$ mode shape

Fig. 8. First three mode shapes of the model structure from FE analysis 


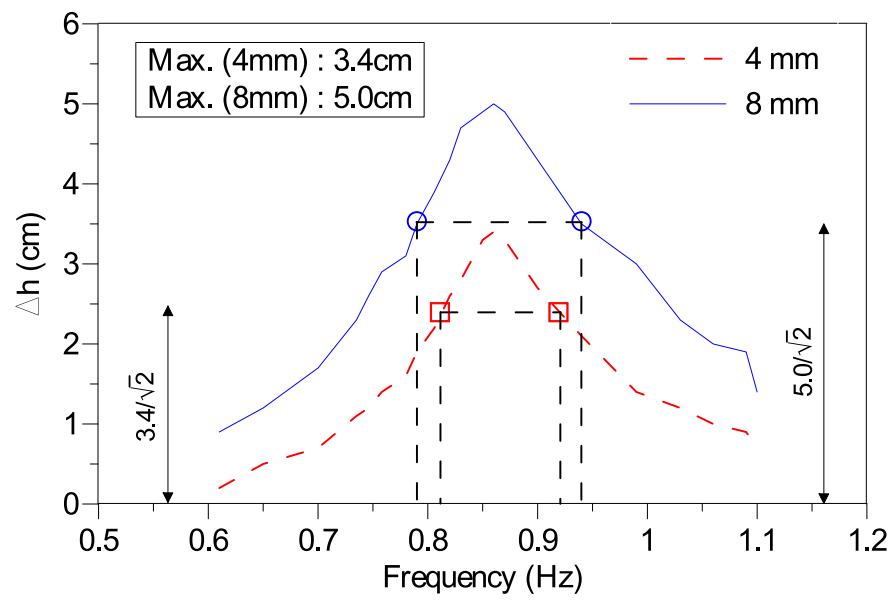

Fig. 9. $\Delta \mathrm{h}$-frequency diagram of TLCD for $4 \mathrm{~mm}$ and $8 \mathrm{~mm}$ excitation amplitudes

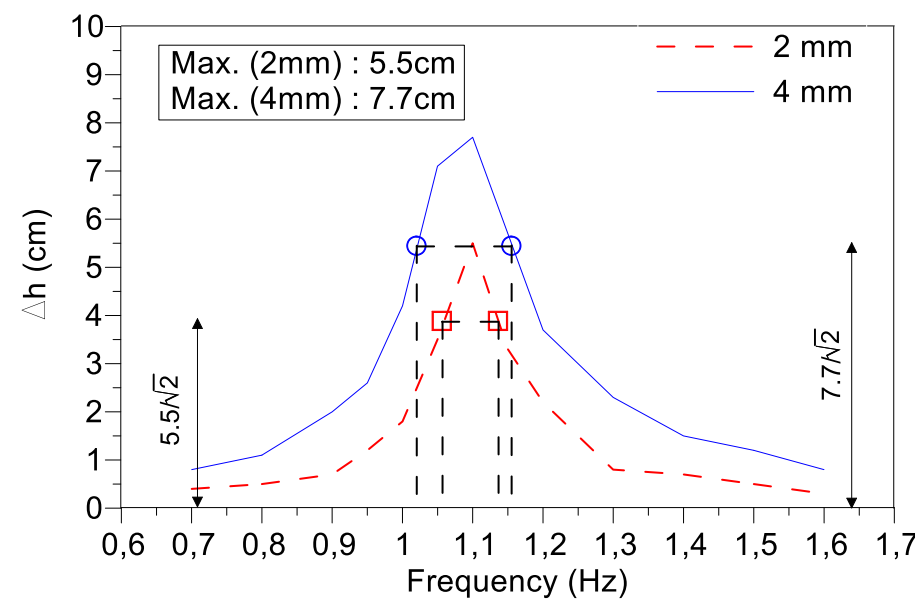

Fig. 10. $\Delta \mathrm{h}$-frequency diagram of ACTLD for $2 \mathrm{~mm}$ and $4 \mathrm{~mm}$ excitation amplitudes

Table 3. Maximum dynamic response and damping ratios of the model structure without absorber for different angles of excitation

\begin{tabular}{|c|c|c|c|c|c|c|c|c|}
\hline \multirow{2}{*}{$\begin{array}{c}\text { Frequency } \\
(\mathrm{Hz})\end{array}$} & $\begin{array}{c}\text { Accel. } \\
(\mathrm{g})\end{array}$ & $\begin{array}{c}\text { Velocity } \\
(\mathrm{cm} / \mathrm{sec})\end{array}$ & $\begin{array}{c}\text { Displacement } \\
(\mathrm{mm})\end{array}$ & $\begin{array}{c}\text { Damping } \\
\text { ratio }(\%)\end{array}$ & $\begin{array}{c}\text { Accel. } \\
(\mathrm{g})\end{array}$ & $\begin{array}{c}\text { Velocity } \\
(\mathrm{cm} / \mathrm{sec})\end{array}$ & $\begin{array}{c}\text { Displacement } \\
(\mathrm{mm})\end{array}$ & $\begin{array}{c}\text { Damping } \\
\text { ratio (\%) }\end{array}$ \\
\hline 0 & 1.299 & 60.740 & 39.190 & 0.699 & 2.292 & 114.960 & 76.720 & 0.739 \\
\hline 15 & 1.281 & 68.690 & 47.300 & 0.499 & 2.317 & 121.880 & 78.560 & 0.695 \\
\hline 30 & 0.919 & 54.630 & 37.490 & 0.512 & 1.910 & 105.310 & 66.390 & 0.699 \\
\hline 45 & 0.620 & 36.540 & 25.830 & 0.713 & 1.358 & 70.440 & 42.460 & 0.450 \\
\hline 60 & 0.278 & 16.360 & 11.120 & 0.405 & 0.620 & 34.160 & 20.330 & 0.775 \\
\hline 75 & 0.123 & 5.710 & 0.560 & 0.671 & 0.207 & 9.730 & 0.553 & 0.939 \\
\hline 90 & 0.092 & 1.419 & 0.420 & 3.267 & 0.111 & 2.612 & 0.600 & 2.577 \\
\hline
\end{tabular}


Table 4. Maximum dynamic response and damping ratios of the structure with TLCD absorber for different excitation directions

\begin{tabular}{ccccccccc}
\hline \multirow{2}{*}{$\begin{array}{c}\text { Frequency } \\
(\mathrm{Hz})\end{array}$} & $\begin{array}{c}\text { Accel. } \\
(\mathrm{g})\end{array}$ & $\begin{array}{c}\text { Velocity } \\
(\mathrm{cm} / \mathrm{sec})\end{array}$ & $\begin{array}{c}\text { Displacement } \\
(\mathrm{mm})\end{array}$ & $\begin{array}{c}\text { Damping } \\
\text { ratio }(\%)\end{array}$ & $\begin{array}{c}\text { Accel. } \\
(\mathrm{g})\end{array}$ & $\begin{array}{c}\text { Velocity } \\
(\mathrm{cm} / \mathrm{sec})\end{array}$ & $\begin{array}{c}\text { Displacement } \\
(\mathrm{mm})\end{array}$ & $\begin{array}{c}\text { Damping } \\
\text { ratio }(\%)\end{array}$ \\
\hline 0 & 0.207 & 21.25 & 19.69 & 3.95 & 0.368 & 31.95 & 30.15 & 4.85 \\
\hline 15 & 0.208 & 20.36 & 19.30 & 4.92 & 0.415 & 31.65 & 28.75 & 6.34 \\
\hline 30 & 0.166 & 15.64 & 14.40 & 3.83 & 0.241 & 23.23 & 22.39 & 4.70 \\
\hline 45 & 0.139 & 12.69 & 12.18 & 3.64 & 0.225 & 17.64 & 17.70 & 5.48 \\
\hline 60 & 0.055 & 3.80 & 4.46 & 3.34 & 0.105 & 7.46 & 7.37 & 3.59 \\
\hline 75 & 0.050 & 2.02 & 1.50 & 2.70 & 0.077 & 3.84 & 2.89 & 3.68 \\
\hline 90 & 0.050 & 1.63 & 0.77 & 3.19 & 0.110 & 3.37 & 1.40 & 2.67 \\
\hline
\end{tabular}

Table 5. Maximum dynamic response and damping ratios of the structure with ACTLD absorber for different excitation directions

\begin{tabular}{ccccccccc}
\hline \multirow{2}{*}{$\begin{array}{c}\text { Frequency } \\
(\mathrm{Hz})\end{array}$} & $\begin{array}{c}\text { Accel. } \\
(\mathrm{g})\end{array}$ & $\begin{array}{c}\text { Velocity } \\
(\mathrm{cm} / \mathrm{sec})\end{array}$ & $\begin{array}{c}\text { Displacement } \\
(\mathrm{mm})\end{array}$ & $\begin{array}{c}\text { Damping } \\
\text { ratio }(\%)\end{array}$ & $\begin{array}{c}\text { Accel. } \\
(\mathrm{g})\end{array}$ & $\begin{array}{c}\text { Velocity } \\
(\mathrm{cm} / \mathrm{sec})\end{array}$ & $\begin{array}{c}\text { Displacement } \\
(\mathrm{mm})\end{array}$ & $\begin{array}{c}\text { Damping } \\
\text { ratio }(\%)\end{array}$ \\
\hline 0 & 0.156 & 13.37 & 14.52 & 4.45 & 0.210 & 19.93 & 23.14 & 5.35 \\
\hline 15 & 0.123 & 11.56 & 12.57 & 4.15 & 0.200 & 18.32 & 19.46 & 5.95 \\
\hline 30 & 0.095 & 8.10 & 9.06 & 5.65 & 0.150 & 13.42 & 16.12 & 5.65 \\
\hline 45 & 0.078 & 6.38 & 7.80 & 3.60 & 0.120 & 10.14 & 10.91 & 5.95 \\
\hline 60 & 0.053 & 4.47 & 5.62 & 3.30 & 0.086 & 6.88 & 7.55 & 6.15 \\
\hline 75 & 0.035 & 2.06 & 2.34 & 4.10 & 0.063 & 3.39 & 3.25 & 4.40 \\
\hline 90 & 0.031 & 1.37 & 1.23 & 8.80 & 0.061 & 1.36 & 0.64 & 10.80 \\
\hline
\end{tabular}

Tables 4 and 5 present the maximum dynamic responses and damping ratios of the model structure with TLCD and ACTLD absorbers for different excitation directions, respectively. The change in dynamic responses due to the absorber installation to the structure is shown Figs. 11 and 12 for $2 \mathrm{~mm}$ excitation amplitude. It is seen from the figures that both TLCD and ACTLD absorbers reduce the dynamic responses of the structure in a significant extent for ground motions with angles up to $75^{\circ}$.

Fig. 13 shows the resonant response time histories and maximum displacement-frequency ratio diagram of the model structure with TLCD for $1 \mathrm{~mm}$ excitation amplitude with the angle of $0^{\circ}$. Table 9 summarizes the dynamic characteristics of the coupled system for the considered case. As seen, the experimentally measured resonant frequency is $1.563 \mathrm{~Hz}$. For FE modelling in ANSYS $\AA$, TLCD was assumed to be an additional mass on the model structure. In Table 10, the first three vibration frequencies calculated by FEM are given for the $0^{\circ}$ direction of excitation. According to FE modal analysis results, the numerical calculated resonant frequency of the structureTLCD system is $1.547 \mathrm{~Hz}$, and it agrees with that of the experimental measurements. Thus, we approximately verify our experimental measurements. Then, the measurements were performed for the other excitation directions of $15^{\circ}$, $30^{\circ}, 45^{\circ}, 60^{\circ}, 75^{\circ}$ and $90^{\circ}$ in case of $1 \mathrm{~mm}$ and 2 $\mathrm{mm}$ amplitudes, respectively. Fig. 14 shows the maximum displacement-frequency ratio diagram for different excitation directions. According to these results, the displacement responses of the structure-TLCD coupled system decrease with increasing the angle of excitation direction. Installing TLCD on the structure reduces its resonant frequency from $2.61 \mathrm{~Hz}$ to $1.563 \mathrm{~Hz}$. Damping ratios of the coupled system change in the range of $2.70 \%-4.94 \%$ for $1 \mathrm{~mm}$-amplitude and $2.67 \%-6.34 \%$ for $2 \mathrm{~mm}$-amplitude, respectively, considering different excitation angles (see Table 4). 


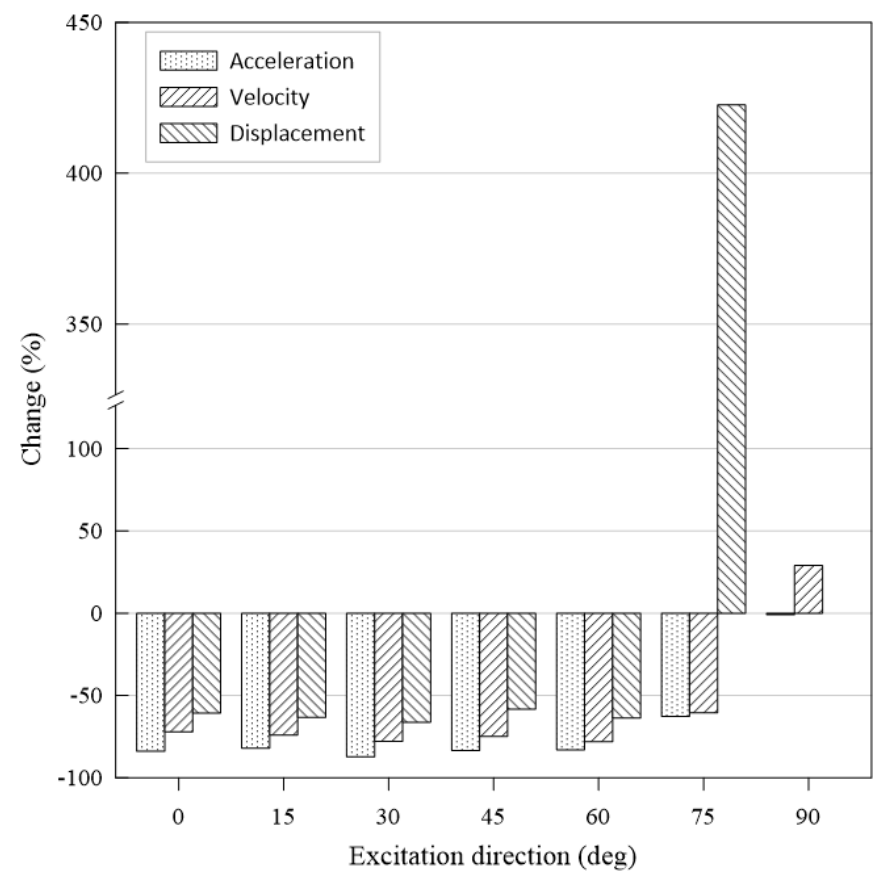

Fig. 11. Change in dynamics responses of the model structure-TLCD coupled system for $2 \mathrm{~mm}$ excitation amplitude

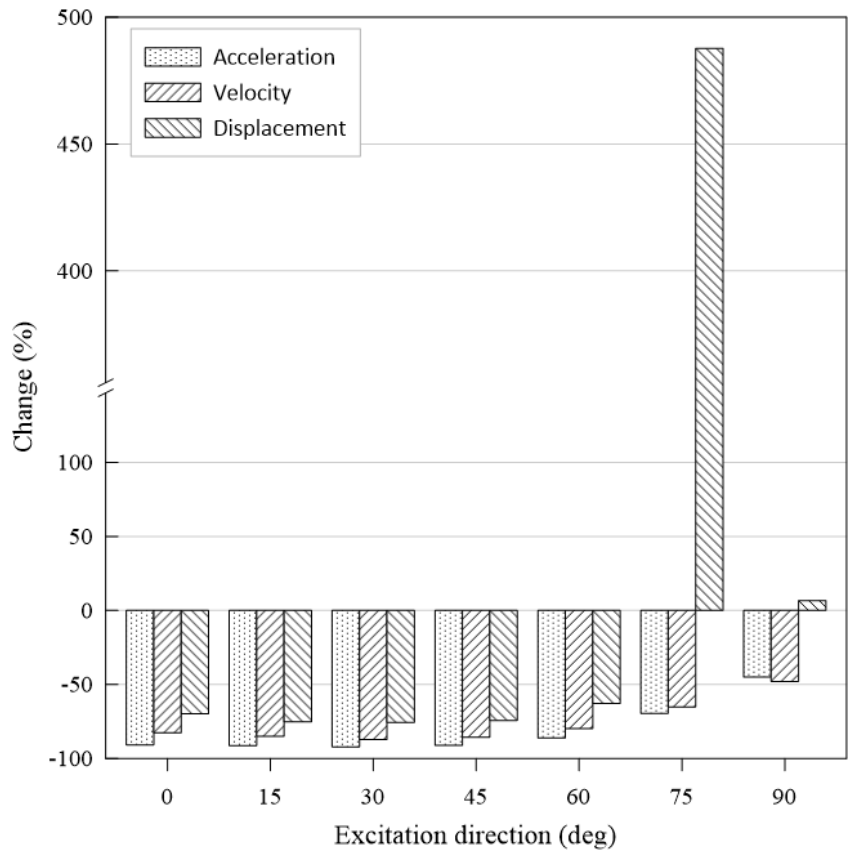

Fig. 12. Change in dynamics responses of the model structure-ACTLD coupled system for $2 \mathrm{~mm}$ excitation amplitude 
Table 6. Comparison of the numerical and experimental natural frequencies $(\mathrm{Hz})$ of the model structure

\begin{tabular}{cccccc}
\hline \multirow{2}{*}{ Mode } & \multirow{2}{*}{ FEM } & \multicolumn{2}{c}{ EFDD } & \multicolumn{2}{c}{ SSI } \\
\cline { 3 - 6 } & & Frequency & Difference (\%) & Frequency & Difference (\%) \\
\hline 1 & 2.633 & 2.596 & 1.40 & 2.613 & 0.76 \\
2 & 7.548 & 6.916 & 9.14 & 6.901 & 9.37 \\
3 & 7.573 & 8.440 & 10.00 & 8.390 & 9.74 \\
\hline
\end{tabular}

Table 7. Damping ratio $\zeta$ and head-loss coefficient $\delta$ of the designed TLCD

\begin{tabular}{ccccccc}
\hline $\begin{array}{c}\text { Amplitude } \\
(\mathrm{mm})\end{array}$ & $\Delta h_{\max }(\mathrm{cm})$ & $\omega_{1}(\mathrm{~Hz})$ & $\omega_{2}(\mathrm{~Hz})$ & $\omega_{R}(\mathrm{~Hz})$ & $\zeta(\%)$ & $\delta$ \\
\hline 4 & 3.4 & 0.81 & 0.92 & 0.86 & 6.39 & 5.20 \\
8 & 5.0 & 0.79 & 0.94 & 0.86 & 8.72 & 4.81 \\
\hline
\end{tabular}

Table 8. Damping ratio $\zeta$ and head-loss coefficient $\delta$ of the designed ACTLD

\begin{tabular}{ccccccc}
\hline $\begin{array}{c}\text { Amplitude } \\
(\mathrm{mm})\end{array}$ & $\Delta h_{\max }(\mathrm{cm})$ & $\omega_{1}(\mathrm{~Hz})$ & $\omega_{2}(\mathrm{~Hz})$ & $\omega_{R}(\mathrm{~Hz})$ & $\zeta(\%)$ & $\delta$ \\
\hline 4 & 3.4 & 0.81 & 0.92 & 0.86 & 6.39 & 5.20 \\
8 & 5.0 & 0.79 & 0.94 & 0.86 & 8.72 & 4.81 \\
\hline
\end{tabular}

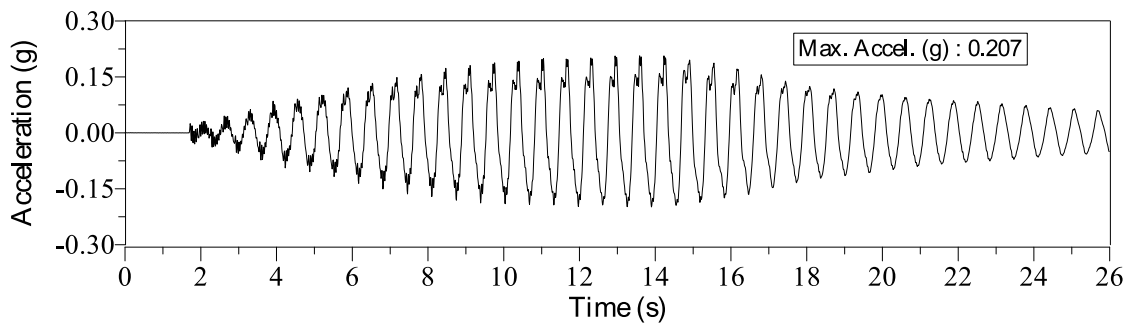

(a) Acceleration time history

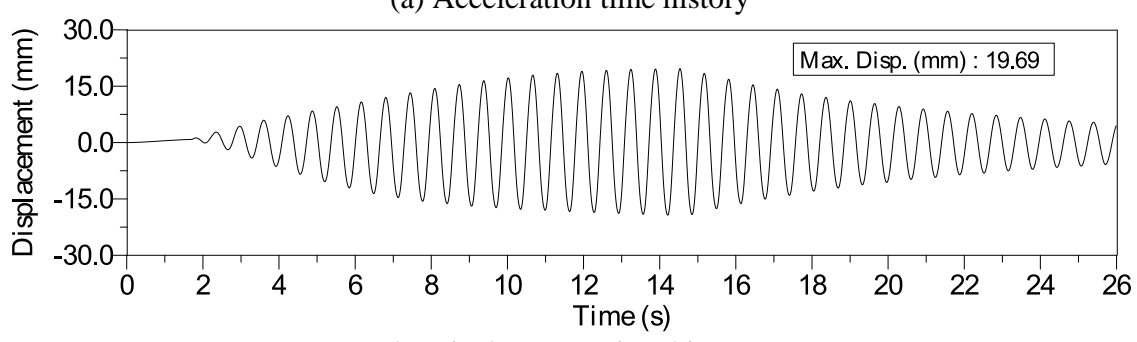

(b) Displacement time history

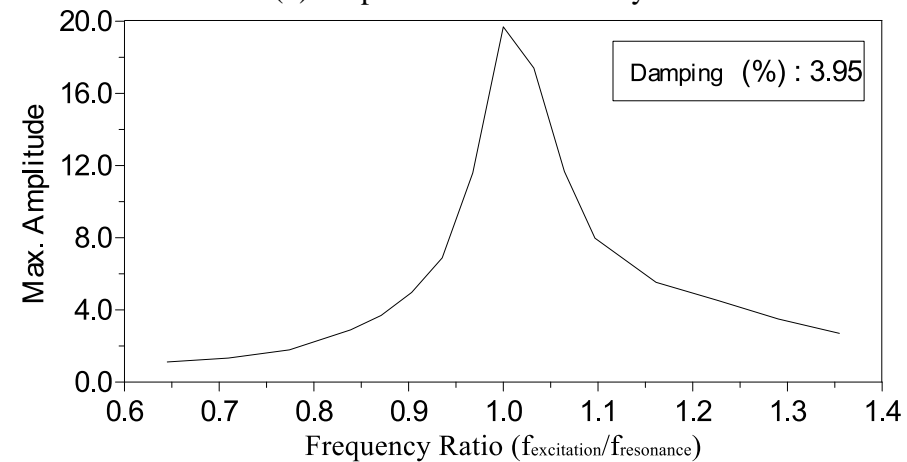

(c) Maximum amplitude-frequency ratio diagram

Fig. 13. Acceleration and displacement time histories and maximum amplitude-frequency ratio diagram of the model structure with TLCD for the resonant frequency $\left(1 \mathrm{~mm}\right.$ amplitude with the angle of $\left.0^{\circ}\right)$ 
Table 9. Dynamic characteristics of the model structure-TLCD coupled system for the resonant frequency (1 mm excitation amplitude with the angle $0^{\circ}$ )

\begin{tabular}{|c|c|c|c|c|c|c|c|}
\hline \multicolumn{4}{|c|}{ Damping } & \multirow{2}{*}{$\begin{array}{l}\text { Acceleration } \\
(\mathrm{g})\end{array}$} & \multirow{2}{*}{$\begin{array}{l}\text { Velocity } \\
(\mathrm{cm} / \mathrm{sec})\end{array}$} & \multirow{2}{*}{$\begin{array}{l}\text { Displacement } \\
(\mathrm{mm})\end{array}$} & \multirow{2}{*}{$\begin{array}{l}\text { Resonant } \\
\text { frequency } \\
(\mathrm{Hz})\end{array}$} \\
\hline$\omega_{1}(\mathrm{~Hz})$ & $\omega_{2}(\mathrm{~Hz})$ & $\omega_{R}(\mathrm{~Hz})$ & $\zeta(\%)$ & & & & \\
\hline 0.974 & 1.053 & 1.0 & 3.95 & 0.207 & 21.25 & 19.69 & 1.563 \\
\hline
\end{tabular}

Table 10. Modal characteristics of the model structure with TLCD calculated by FEM

\begin{tabular}{cccc}
\hline Mode & Period $(\mathrm{s})$ & Frequency $(\mathrm{Hz})$ & Mass Participation ratio $(\%)$ \\
\hline 1 & 0.646 & 1.547 & 87.6 \\
\hline 2 & 0.108 & 9.276 & 94.0 \\
\hline 3 & 0.069 & 14.533 & 98.0 \\
\hline
\end{tabular}

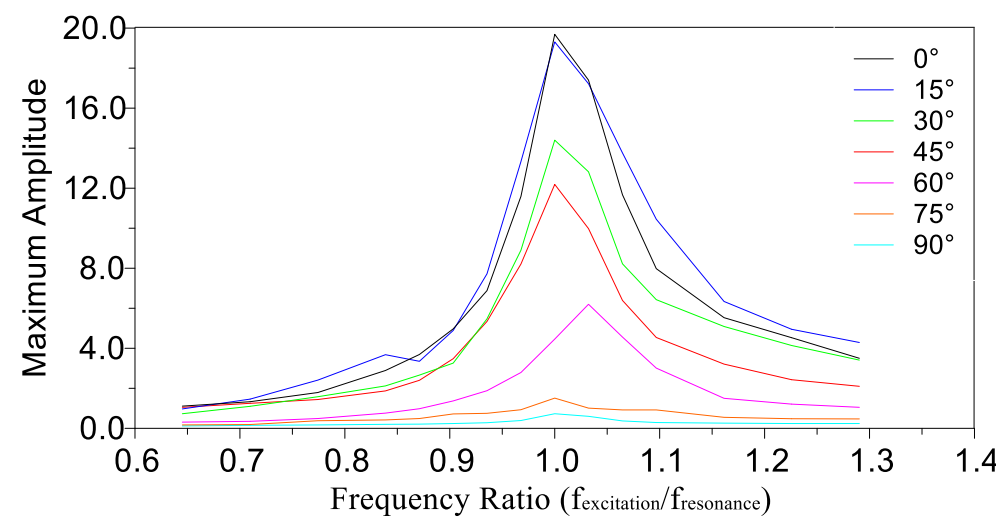

(a) $1 \mathrm{~mm}$ excitation amplitude

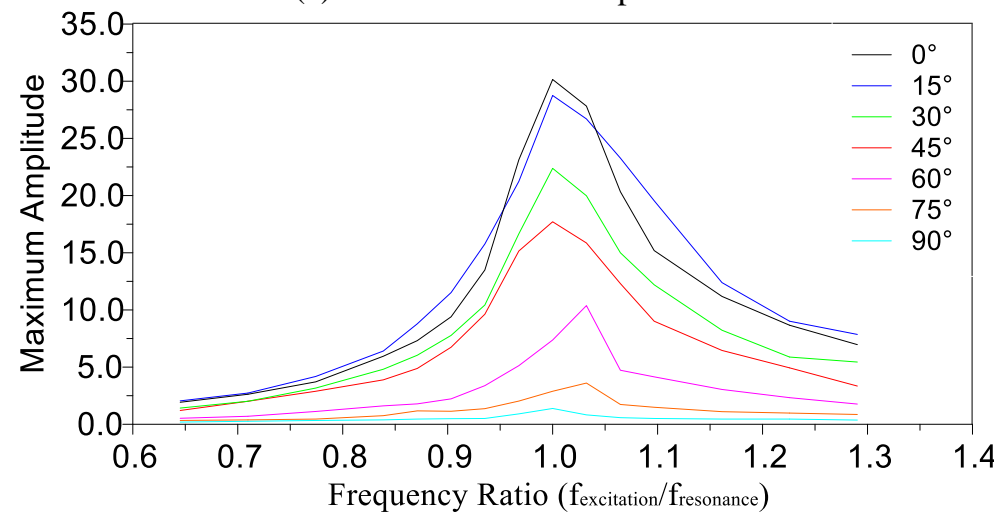

(b) $2 \mathrm{~mm}$ excitation amplitude

Fig. 14. Maximum displacement-frequency ratio diagram of the model structure with TLCD for different excitation angles

Fig. 15 shows the resonant response time histories and maximum displacement-frequency ratio diagram of the model structure with ACTLD for $1 \mathrm{~mm}$ excitation amplitude with the angle of $0^{\circ}$. Table 11 summarizes the dynamic characteristics of the model structure-ACTLD coupled system in the resonant frequency for $1 \mathrm{~mm}$ excitation amplitude with the angle of $0^{\circ}$. As seen, the experimentally identified resonant frequency is $1.50 \mathrm{~Hz}$. Again, considering the ACTLD is an additional mass on the structure, the FE modal analyses were performed in ANSYS ${ }^{\circ}$. In Table 12, the first three vibration frequencies calculated by FEM are presented for the coupled system. As seen, the 
calculated resonant frequency of the coupled system is $1.55 \mathrm{~Hz}$, and it shows a good agreement with that of measurements. Then, the measurements were repeated for other angles of $15^{\circ}, 30^{\circ}, 45^{\circ}, 60^{\circ}$, $75^{\circ}$ and $90^{\circ}$ angles with $1 \mathrm{~mm}$ and $2 \mathrm{~mm}$ excitation amplitudes, respectively. In Fig. 16, the maximum displacement-frequency ratio diagrams are plotted for $1 \mathrm{~mm}$ and $2 \mathrm{~mm}$ excitation amplitudes, respectively. According to these graphs, the displacement responses significantly decrease with installation of ACTLD when the angle of motion changes from $0^{\circ}$ to $90^{\circ}$. Installing ACTLD on the model structure causes to reduce its resonant frequency $2.61 \mathrm{~Hz}$ to $1.50 \mathrm{~Hz}$, which is slightly better than installing TLCD. Damping ratios of the coupled system change in the range of $3.30 \%$ $8.80 \%$ for $1 \mathrm{~mm}$-amplitude and $4.40 \%-10.80 \%$ for $2 \mathrm{~mm}$-amplitude, respectively considering different excitation angles (see Table 5).

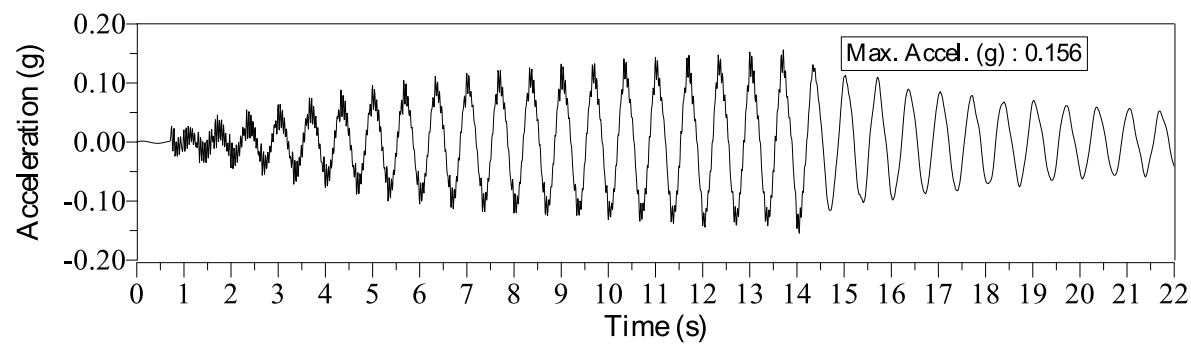

(a) Acceleration time history

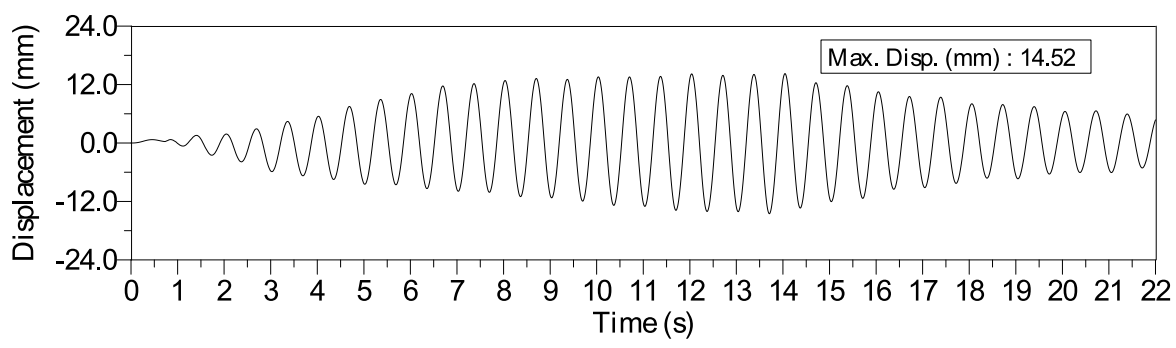

(b) Displacement time history

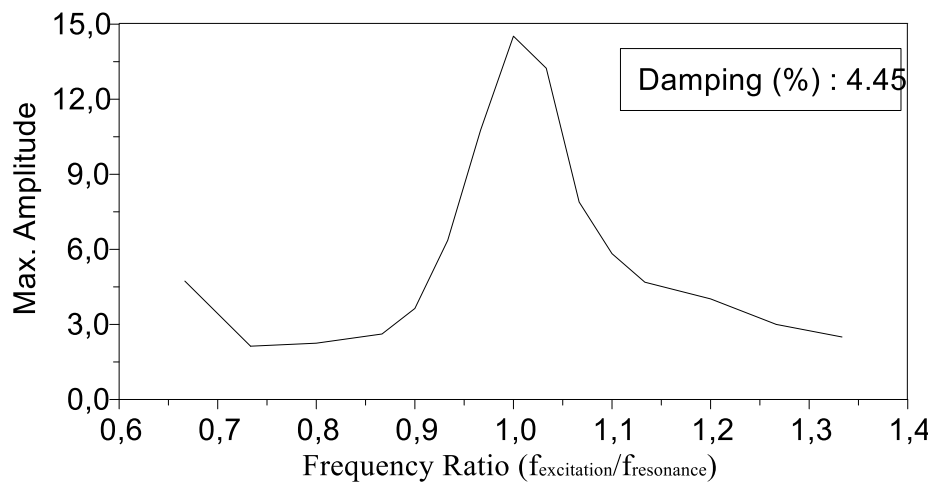

(c) Maximum amplitude-frequency ratio diagram

Fig. 15. Acceleration and displacement time histories and maximum amplitude-frequency ratio diagram of the model structure with ACTLD for the resonant frequency $\left(1 \mathrm{~mm}\right.$ excitation amplitude with the angle $\left.0^{\circ}\right)$ 
Table 11. Dynamic characteristics of the model structure-ACTLD coupled system for the resonant frequency (1 mm excitation amplitude with the angle of $0^{\circ}$ )

\begin{tabular}{|c|c|c|c|c|c|c|c|}
\hline \multicolumn{4}{|c|}{ Damping } & \multirow{2}{*}{$\begin{array}{c}\text { Acceleration } \\
\text { (g) }\end{array}$} & \multirow{2}{*}{$\begin{array}{l}\text { Velocity } \\
(\mathrm{cm} / \mathrm{sec})\end{array}$} & \multirow{2}{*}{$\begin{array}{l}\text { Displacement } \\
(\mathrm{mm})\end{array}$} & \multirow{2}{*}{$\begin{array}{l}\text { Resonant } \\
\text { frequency } \\
(\mathrm{Hz})\end{array}$} \\
\hline$\omega_{1}(\mathrm{~Hz})$ & $\omega_{2}(\mathrm{~Hz})$ & $\omega_{R}(\mathrm{~Hz})$ & $\zeta(\%)$ & & & & \\
\hline 0.963 & 1.052 & 1.0 & 4.45 & 0.156 & 13.37 & 14.52 & 1.50 \\
\hline
\end{tabular}

Table 12. Modal characteristics of the model structure with ACTLD calculated by FEM

\begin{tabular}{cccc}
\hline Mode & Period $(\mathrm{s})$ & Frequency $(\mathrm{Hz})$ & Mass Participation ratio $(\%)$ \\
\hline 1 & 0.645 & 1.55 & 87.6 \\
2 & 0.111 & 9.03 & 94.0 \\
3 & 0.071 & 14.15 & 98.0 \\
\hline
\end{tabular}

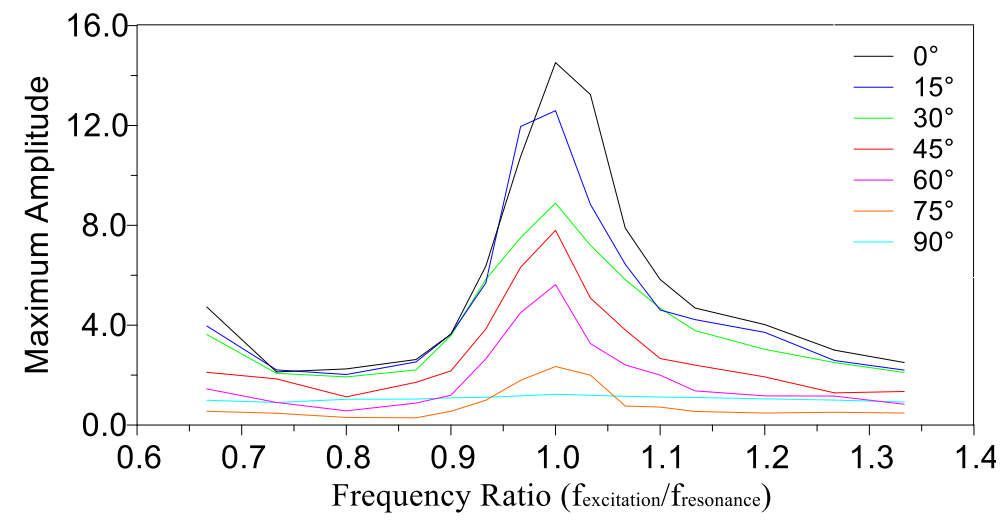

(a) $1 \mathrm{~mm}$ excitation amplitude

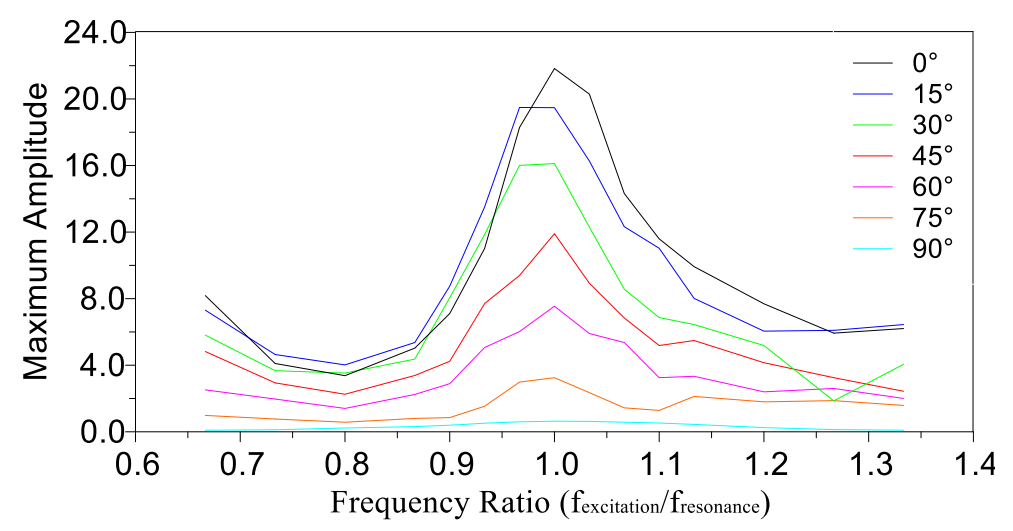

(b) $2 \mathrm{~mm}$ excitation amplitude

Fig. 16. Maximum displacement-frequency ratio diagram of the model structure with ACTLD for different excitation angles

Figures 17-20 compare the changes in dynamic responses and damping ratio for the structureabsorber coupled system. In the figures, $\mathrm{S}$ w/ TLCD represents the structure with TLCD, and S w/
ACTLD represents the structure with ACTLD. The comparisons are made for $2 \mathrm{~mm}$ excitation amplitude only. Fig. 17 shows the comparison of the changes in acceleration responses of the 
structure when it is installed with TLCD and ACTLD. As seen, ACTLD is better than TLCD for all excitation angles of ground motion. Fig. 18 presents the comparison of the changes in velocity responses of the structure with absorbers considered. Again, we can see that ACTLD shows better performance than TLCD. Here, we have an exception for the angle of $90^{\circ}$. In Fig. 19, the comparison of the changes in displacement responses of the structure-absorber coupled system are given. According to this graph, it is seen that ACTLD is better than TLCD. Here, for the angles $75^{\circ}$ and $90^{\circ}$, we have positive change percentage in the displacements that means the systems' displacement increases with respect to the structure without absorber. Finally, Fig. 20 shows the comparison of the changes in damping ratios for both cases. As seen, ACTLD generally provides better damping performance than TLCD when the system is subjected to inclined ground motion. Especially for the angles greater than $45^{\circ}$, the effectiveness of ACTLD in providing damping drastically increases.

Vibration absorbers are, in general, designed such that they have the equal or close frequency value to the resonant frequency of the main structure to be controlled. In this study, both absorbers were designed to have different frequencies from the resonant frequency of the model structure to test their robustness. According to the results of the study, even in such case, both devices show good control performance in vibration reduction. Since ACTLD is better than TLCD based on the discussion given the previous paragraphs, we can say that ACTLD shows more robust performance than TLCD.

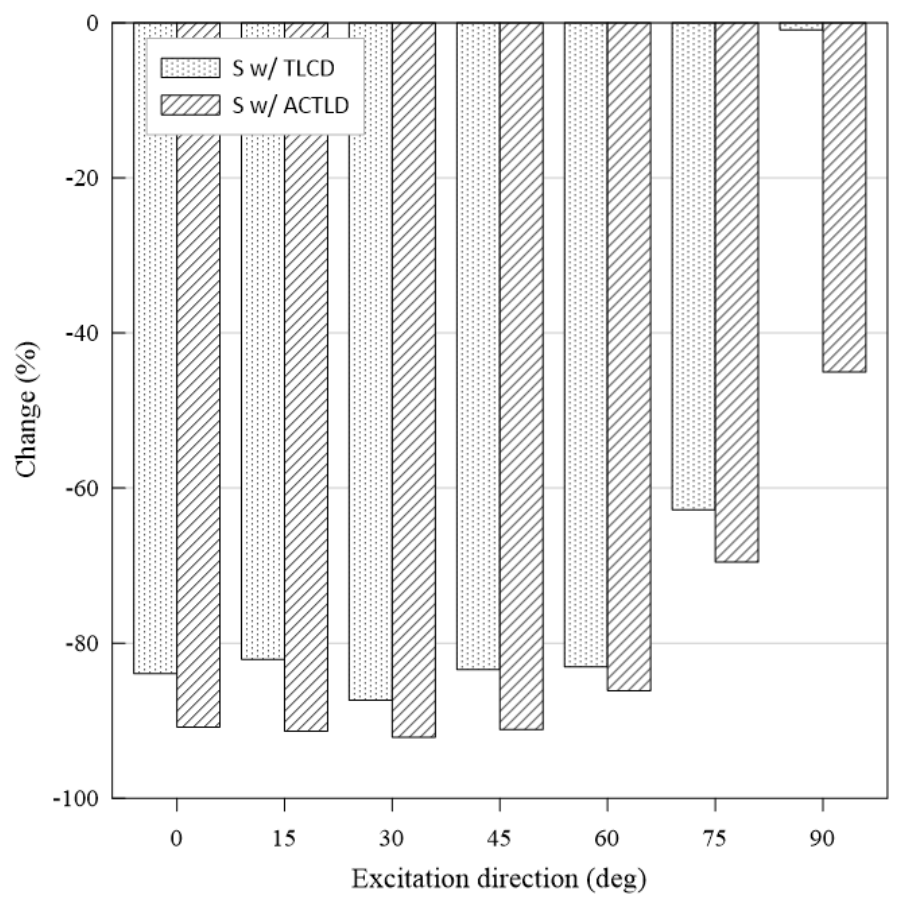

Fig. 17. Comparison of the changes in acceleration response of the model structure with TLCD and ACTLD for ground motion with $2 \mathrm{~mm}$ excitation amplitude 


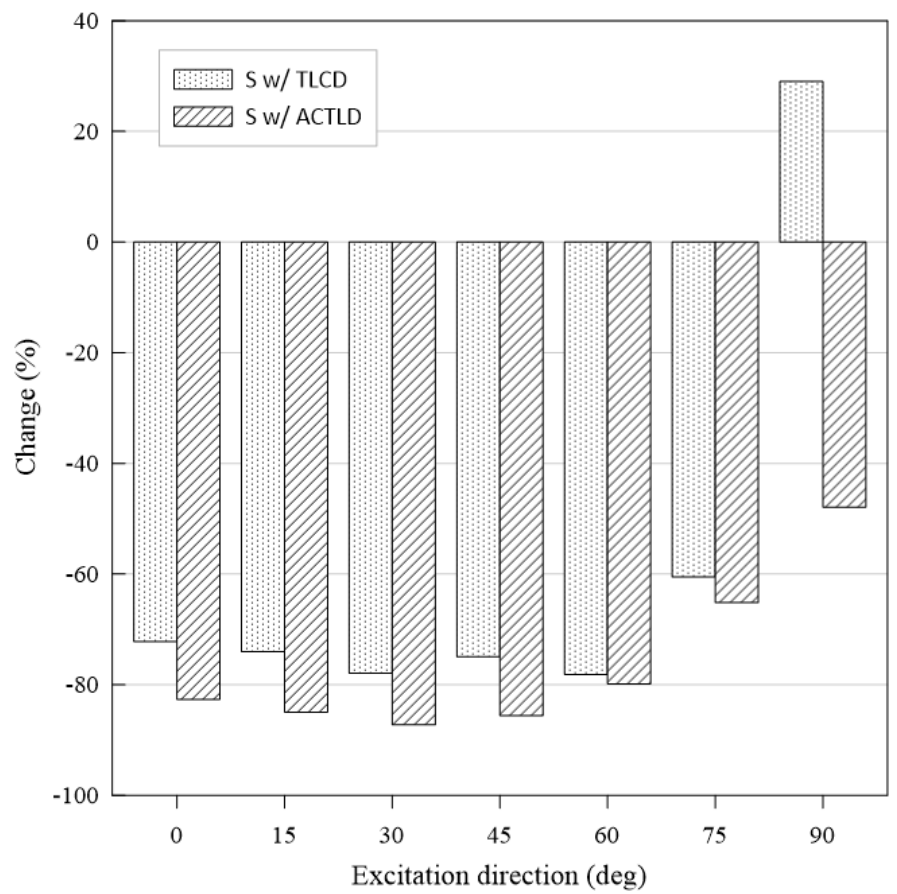

Fig. 18. Comparison of the changes in velocity response of the model structure with TLCD and ACTLD for ground motion with $2 \mathrm{~mm}$ excitation amplitude

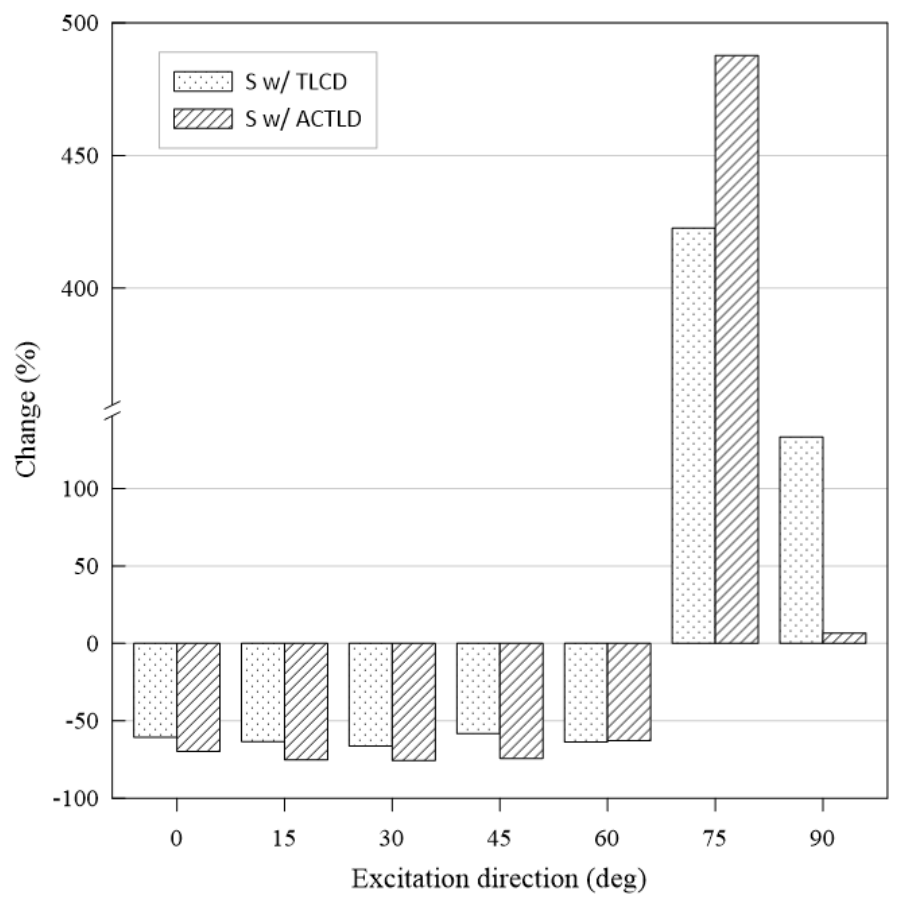

Fig. 19. Comparison of the changes in displacement response of the model structure with TLCD and ACTLD for ground motion with $2 \mathrm{~mm}$ excitation amplitude 


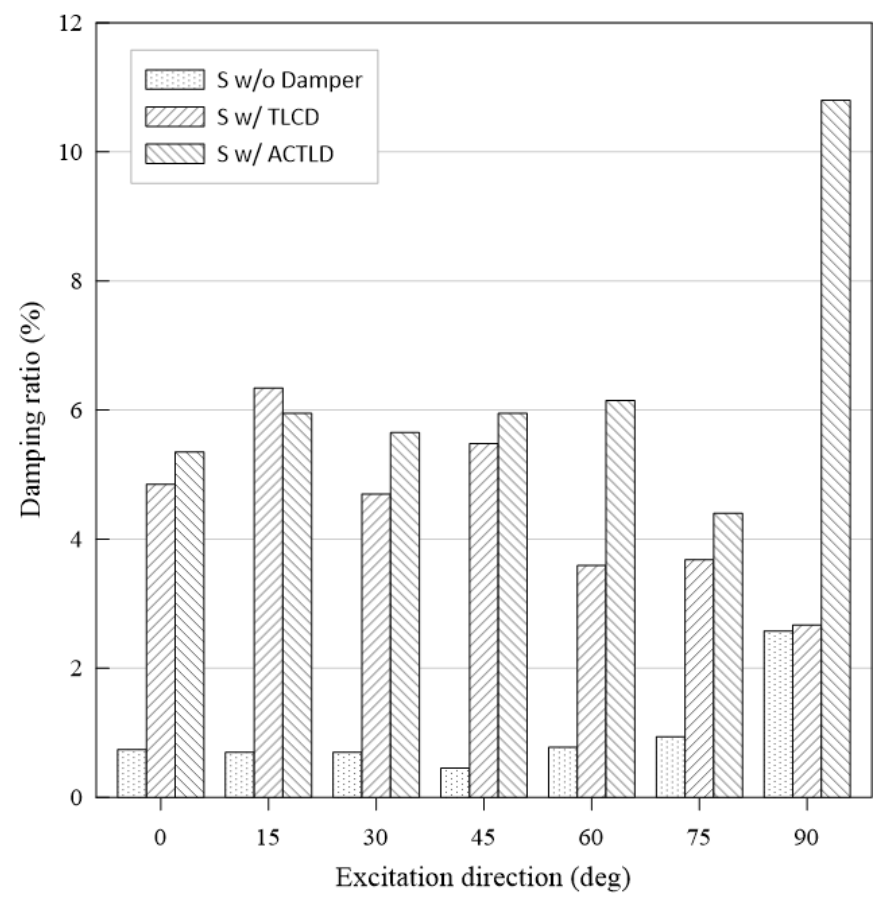

Fig. 20. Comparison of the damping ratios of the model structure with and without absorbers for ground motion with 2 mm excitation amplitude

\section{Conclusion}

In this study, the control performances of annular cylindrical tuned liquid dampers (ACTLDs) and tuned liquid column dampers (TLCDs) are compared when the main structure is subject to a ground motion with inclined direction. ACTLDs are designed such that total water lengths in each direction be equal to that of TLCD. Experimental analyses are performed on a model structure with and without absorbers. Ground motion is simulated by a shaking table. The following conclusions can be drawn from the study:

- Both TLCD and ACTLD absorbers reduce the dynamic responses of the structure considerably for ground motions with a certain value of inclination angle, which depends on the amplitude of the external excitation.

- The damping ratios increase in a great extent for installation of absorbers to the structure for all inclination angles. The general trend of change in damping ratio is first increasing then decreasing when the angle increases.
- Resonant frequency of the structure-absorber coupled system is slightly smaller in case of ACTLD installation than that of TLCD.

- ACTLD generally shows better performance in reduction of dynamic responses of the structure than TLCD for inclined ground motions effect.

- ACTLD generally provides better damping performance than TLCD when the system is subject to inclined ground motion. Especially for the inclination angles greater than $45^{\circ}$, the effectiveness of ACTLD in providing damping drastically increases.

- ACTLD absorber always provides the oscillation of water instead of the sloshing due to its U-shaped form in each longitudinal section. It is desirable behavior for liquid column dampers for vibration control.

- ACTLD shows more robust performance than TLCD to the change of the excitation angles.

- This study only performs an experimental evaluation of using ACTLDs and TLCDs in vibration control of a model structure under inclined ground motions. Further analytical and 
numerical models should be developed and experimentally validated to extend the results of this study to real structures, which is still in progress.

\section{Declaration of conflicting interests}

The author(s) declared no potential conflicts of interest with respect to the research, authorship, and/or publication of this article.

\section{References}

[1] Roffel A.J, Narasimhan S, Haskett T (2013) Performance of pendulum tuned mass dampers in reducing the responses of flexible structures. Journal of Structural Engineering 139:04013019.

[2] KahyaV, Araz O (2017) Series tuned mass dampers in train-induced vibration control of railway bridges. Structural Engineering and Mechanics 61:453-461.

[3] ChenH, Jia S, He X (2019) Dynamic characteristics of multiple inerter-based dampers for suppressing harmonically forced oscillations. Structural Engineering and Mechanics 72:747-762.

[4] Cao L, Li C, Chen X (2020) Performance of multiple tuned mass dampers-inerters for structures under harmonic ground acceleration. Smart Structures and Systems 26:49-61.

[5] De Domenico D, Qiao H, Wang Q, Zhu Z, Marano G (2020) Optimal design and seismic performance of Multi-Tuned Mass Damper Inerter (MTMDI) applied to adjacent high-rise buildings. The Structural Design of Tall and Special Buildings 29:e1781.

[6] Gao H, Kwok KCS, Samali B (1997) Optimization of tuned liquid column dampers, Engineering Structures 19:476-486.

[7] Ruiz R.O, Lopez-Garcia D, Taflanidis AA (2016) Modeling and experimental validation of a new type of tuned liquid damper. Acta Mechanica 227:3275-3294.

[8] Altunişik AC, Yetişken A, Kahya V (2018) Experimental study on control performance of tuned liquid column dampers considering different excitation directions. Mechanical Systems and Signal Processing 102:59-71.

[9] Wang Q, Tian H, Qiao H, Tiwari ND, Wang Q (2021) Wind-induced vibration control and parametric optimization of connected high-rise buildings with tuned liquid-column-damperinerter. Engineering Structures 226:111352.

[10] Khalid B, Ziegler F (2012) A novel aseismic foundation system for multipurpose asymmetric buildings. Archive of Applied Mechanics 82:14231437.

[11] Connor J, Laflamme S (2014) Tuned Mass Damper Systems, Vol. 9783319062, Springer International Publishing, Cham.

[12] Furtmüller T, Di Matteo A, Adam C, Pirrotta A (2019) Base-isolated structure equipped with tuned liquid column damper: An experimental study. Mechanical Systems and Signal Processing 116:816-831.

[13] Saaed TE, Nikolakopoulos G, Jonasson JE, Hedlund H (2015) A state-of-the-art review of structural control systems. Journal of Vibration and Control 21:919-937.

[14] Sonmez E, Nagarajaiah S, Sun C, Basu B (2016) A study on semi-active Tuned Liquid Column Dampers (sTLCDs) for structural response reduction under random excitations. Journal of Sound and Vibration 362:1-15.

[15] Sakai F, Sun NAC Basu B (1989) Tuned liquid column damper-new type device for suppression of building vibrations. In Proceedings of International Conference on High Rise Buildings.

[16] Balendra T, Wang CM, Cheong HF (1995) Effectiveness of tuned liquid column dampers for vibration control of towers. Engineering Structures 17:668-675.

[17] Chang CC, Hsu CT (1998) Control performance of liquid column vibration absorbers. Engineering Structures 20:580-586.

[18] Hitchcock PA, Kwok KCS, Watkins RD, Samali B (1997) Characteristics of liquid column vibration absorbers (LCVA)-Part I. Engineering Structures 19:126-134.

[19] Hitchcock PA, Kwok KCS, Watkins RD, Samali B (1997) Characteristics of liquid column vibration absorbers (LCVA)-Part II. Engineering Structures 19:135-144.

[20] Yalla SK, Kareem A (2003) Semiactive tuned liquid column dampers: Experimental study. Journal of Structural Engineering 129:960-971.

[21] Wu JC, Shih MH, Lin YY, Shen YC (2005) Design guidelines for tuned liquid column damper for structures responding to wind. Engineering Structures 27:1893-1905.

[22] Wu JC, Chang CH, Lin YY (2009) Optimal designs for non-uniform tuned liquid column dampers in 
horizontal motion. Journal of Sound and Vibration 326:104-122.

[23] Chaiviriyawong P, Limkatanyu S, Pinkaew T (2008) Simulations of characteristics of tuned liquid column damper using an elliptical flow path estimation method. In the 14th World Conference on Earthquake Engineering.

[24] Al-Saif KA, Aldakkan KA, Foda MA (2011) Modified liquid column damper for vibration control of structures. International Journal of Mechanical Sciences 53:505-512.

[25] Mousavi SA, Zahrai SM, Bargi K (2012) Optimum geometry of tuned liquid column-gas damper for control of offshore jacket platform vibrations under seismic excitation. Earthquake Engineering and Engineering Vibration 11:79-592.

[26] Sarkar A, Gudmestad OT (2013) Pendulum type liquid column damper (PLCD) for controlling vibrations of a structure-Theoretical and experimental study. Engineering Structures 49:221-233.

[27] Mensah AF, Dueñas-Osorio L (2014) Improved reliability of wind turbine towers with tuned liquid column dampers (TLCDs). Structural Safety 47:7886.

[28] Bigdeli Y, Kim D (2016) Damping effects of the passive control devices on structural vibration control: TMD, TLC and TLCD for varying total masses. KSCE Journal of Civil Engineering 20:301-308.
[29] Di Matteo A, Di Paola M, Pirrotta A (2016) Innovative modeling of tuned liquid column damper controlled structures, Smart Structures and Systems 18:117-138.

[30] Behbahani HP, Bin Adnan A, Vafaei M, Pheng O.P, Shad H (2017) Effects of TLCD with maneuverable flaps on vibration control of a SDOF structure. Meccanica 52:1247-1256.

[31] Altunişik AC, Yetişken A, Kahya V (2019) Annular cylindrical liquid column dampers for control of structural vibrations. Iranian Journal of Science and Technology 43:479-490.

[32] ANSYS Mechanical APDL Release 16.0. ANSYS, Inc., 2014.

[33] PULSE Analyzers and Solutions. Brujel and Kjaer, Sound and Vibration Measurement A/S, Denmark, 2006.

[34] OMA Operational Modal Analysis Software. Structural Vibration Solution A/S, Denmark, 2006.

[35] SeismoSignal. Seismosoft Earthquake Engineering Software Solutions, 2016.

[36] Papagiannopoulos GA, Hatzigeorgiou G.D (2011) On the use of the half-power bandwidth method to estimate damping in building structures. Soil Dynamics and Earthquake Engineering 31:10751079. 